\title{
IN SILICO STUDIES OF (S)-2-AMINO-4-(3,5-DICHLOROPHENYL) BUTANOIC ACID AGAINST LAT1 AS A RADIOTHERANOSTIC AGENT OF CANCER
}

\section{HOLIS ABDUL HOLIK ${ }^{1 *}$, FAISAL MAULANA IBRAHIM ${ }^{1}$, ABIB LATIFU FATAH ${ }^{1}$, ARIFUDIN ACHMAD ${ }^{2}$, ACHMAD HUSSEIN SUNDAWA KARTAMIHARDJA ${ }^{2}$}

1Department of Pharmaceutical Analysis and Medicinal Chemistry, Faculty of Pharmacy/Universitas Padjadjaran, Sumedang 45363, (West Java) Indonesia, 2Department of Nuclear Medicine, Faculty of Medicine/Universitas Padjadjaran, Sumedang 45363, (West Java) Indonesia

Email: holis@unpad.ac.id

Received: 18 Aug 2021, Revised and Accepted: 02 Oct 2021

\section{ABSTRACT}

Objective: This study aims to obtain a good activity of radiotheranostic kit for cancer which is built by combining (S)-2-amino-4-(3,5dichlorophenyl) butanoic acid (ADPB) with various bifunctional chelators.

Methods: This study was conducted through in silico method that consists of molecular docking simulation using AutoDock 4 as well as ADMET prediction using vNN-ADMET and Pre-ADMET. Six bifunctional chelators (i.e. CTPA, DOTA, H2CB-TE2A, H2CB-D02A, NOTA, and TETA) were conjugated with ADPB as a carrier molecule and further analyzed through molecular docking and ADMET prediction.

Results: The results showed that the ADPB-NOTA has the best affinity with the Gibbs free energy $(\Delta G)$ of-7.68 kcal/mol with an inhibition constant of $2.36 \mu \mathrm{M}$ and its ability to bind with the gating residue of LAT1 (ASN258) through hydrogen interactions. Besides that, the ADPB-NOTA compound has a good ADME profile and is predicted to be safe for human use.

Conclusion: This study showed that ADPB-NOTA is the most prospective candidate to be used as a radiotheranostic agent.

Keywords: Bifunctional chelators, Cancer, LAT1, In silico, Radiotheranostic

(C) 2021 The Authors. Published by Innovare Academic Sciences Pvt Ltd. Thisis an open access article under the CC BYlicense (https://creativecommons.org/licenses/by/4.0/) DOI: https://dx.doi.org/10.22159/ijap.2021.v13s4.43868 Journal homepage: https://innovareacademics.in/journals/index.php/ijap

\section{INTRODUCTION}

Cancer is the second-highest cause of death worldwide with 9.6 million mortalities in 2018 [1]. A complex mechanism of cancer pathogenesis led to a cause of difficulty in determining the right drug target for cancer. Nowadays, the development of cancer-related drugs in clinical trials still lacks succession (3.4\%) due to its wrongly targeted pathway $[2,3]$. So, developing a new method of intervention for cancer patients is urgently needed.

One of a prospective and valid target for cancer is the Large Amino Acid Transporter type 1 (LAT1) which is a $\mathrm{Na}^{+}$-independent amino acid transporter that can transport a large branched-chain and aromatic neutral amino acids (i.e. histidine, isoleucine, leucine, phenylalanine, tryptophan, tyrosine, methionine and valine) [4-6]. LAT1 and 4F2 cell-surface antigen heavy chain (4F2hc) is a heterodimeric protein complex bridged with a disulfide bond [5]. This target is overexpressed in various cancer cells including oral squamous cell carcinoma [7], esophageal carcinoma [8], gastric cancer [9], prostate cancer [10], non-small cell lung carcinoma [11], biliary tract cancer [12], pancreatic cancer [13], and breast cancer [14]. The overexpression of LAT1 in a cancer cell makes this protein a prospective target for radiotheranostic agents of cancer [15].

Radiopharmaceutical agent is a compound that can deliver radioactive atoms to a cell target (mostly tumor-associated cells) The differences with radiotherapy are the radiation is not given from the outside of the body, but instead is delivered through a systemic or locoregional way. The cytotoxic effect to the cancer cells comes from the $\alpha / \beta$ radiation of its radionuclide, which has already been vehicled through a certain carrier molecule that can interact specifically with a receptor within the target cells or tumor microenvironment. Besides that, diagnosis functionalities are also used for cancer imaging conducted by the delivery of $\gamma$-emitting radionuclide [16]. Currently, radiopharmaceutical agents have been developed to be a radiotheranostic agent (a substance that has a function to cure and diagnose a disease through the utilization of radionuclide emission) [17].

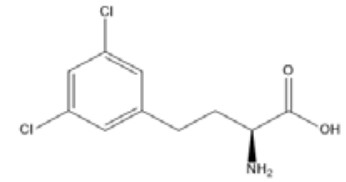

(a)

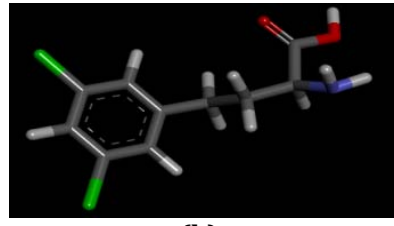

(b)
Fig. 1: Structure of (a) 2 Dimensions and (b) 3 Dimensions (S)2-Amino-4-(3,5-dichlorophenyl) butanoic acid, drawn using ChemDraw 2D and Chem3D tools

One of the most prospective compounds that can be a carrier for the radionuclide against LAT1 is (S)-2-amino-4-(3,5dichlorophenyl)butanoic acid or abbreviated as ADPB (fig. 1). ADPB is a butanoic acid derivative that can inhibit LAT1 with an IC $_{50}$ of $0.64 \pm 0.12 \mathrm{M}$. This value is ten times stronger than its competitor, which is currently have been developed in the clinical trial, namely 2-aminobicyclo-(2.2,1)-heptane-2-carboxylic acid $\left(\mathrm{IC}_{50}=6.8 \pm 0.27 \mathrm{M}\right)$ [18]. Unfortunately, ADPB is unable to make a complex with a metal radionuclide directly. Thus, the presence of bifunctional chelator (BFCA) is needed to complex the radiometal in the kit of radiopharmaceuticals. This study aims to obtain the best radiopharmaceutical kit candidate using BFCA-conjugated ADPB through several stages of in silico research.

\section{MATERIALS AND METHODS}

\section{Structure modification}

ADPB modification was carried out by conjugating 68-Ga compatible BFCA on the amine group of ADPB. Modification of the structure centered on the amine group aims to form an amide bond with a carboxylate group in BFCA so that it is possible to do chemical synthesis, one of which is through the SN1 mechanism. The 68-Ga compatible BFCAs used in this research are NOTA, DOTA, TETA, CTPA, H2Cb-D02A, and H2Cb-TE2A. The results of the structural modifications are available in fig. 2 . 


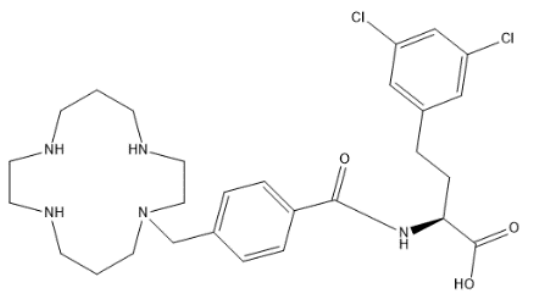

ADPB-CTPA

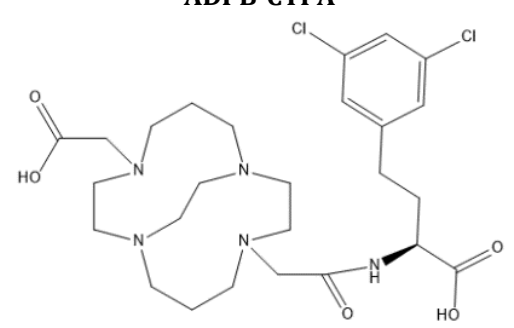

ADPB-H2CB-TE2A<smiles>N[C@@H](CCc1cc(Cl)cc(Cl)c1)C(=O)O</smiles>

ADPB (Lead Compound)

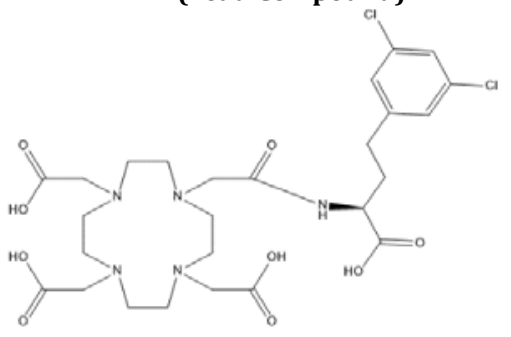

ADPB-DOTA

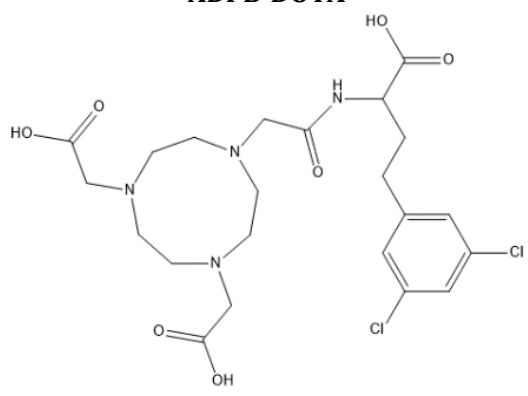

ADPB-NOTA

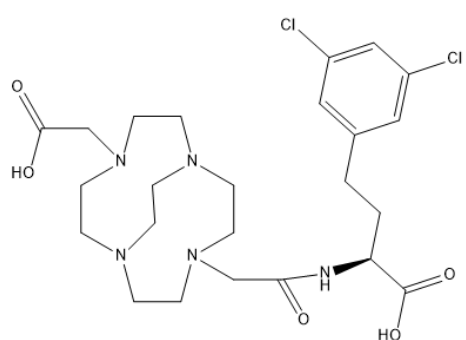

ADPB-H2CB-D02A

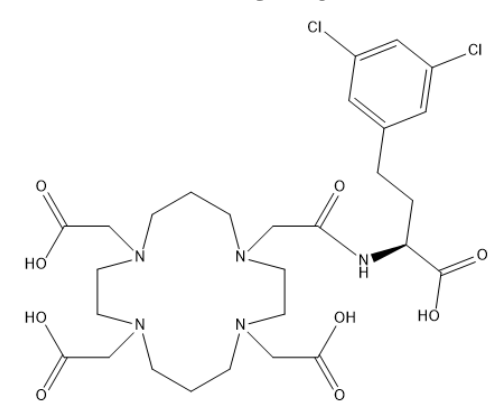

ADPB-TETA

Fig. 2: The structure of ADPB derivatives conjugated with BFCA (NOTA, DOTA, TETA, CTPA, H2Cb-DO2A, and H2Cb-TE2A)

\section{Preparation of the ligand and the target}

The ligands used are six derivatives of ADPB that were conjugated with various chelators. The entire 2D structure of the ligands was built using ChemDraw which was then converted using Chem3D and optimized through the MM2 function. The target used is LAT1 complexed with $4 \mathrm{~F} 2 \mathrm{hc}$ and bound to the BCH ligand as a native inhibitor of LAT1 (PDB ID: 6IRT) downloaded from the Protein Data Bank (www.rcsb.org) [20]. The water molecules present in the protein are removed and the BCH ligand is separated from the receptor using the BIOVIA Discovery Studio Visualizer 2016 Client program. Hence, only the receptor without the ligand will be used in the molecular docking process.

\section{Validation of molecular docking}

The validation method of molecular docking was carried out through a re-docking procedure of the native ligand to the pocket of the target with a specific grid coordinate performed by AutoDock 4.3. The RMSD (Root Mean Square Deviation) of the ligand position after re-docking procedure must be lower than $2.0 \AA$ [21, 22].

\section{Molecular docking simulation}

Ligands and LAT1 were prepared using AutoDock tools 1.5.6 prior to the molecular docking simulation. LAT1 is a macromolecule that is protonated and added to Kollman charges. Meanwhile, all ligands were protonated by adding hydrogen atoms and charged through the Gasteiger method. Best grid coordinates obtained from previous validation were used to determine the pocket that was addressed at $(x=146,324 ; y=143,105 ; y=134,340)$. Docking parameter data is based on the Lamarckian Genetic Algorithm (LGA) with 1000 runs, 2,500,000 energy evaluation, 150 population size, 0.02 gene mutation rate, and 0.8 rates of crossover. Then, all of the docked ligands were visualized using Biovia Discovery Studio 2016. Molecular docking results were ranked based on the series of docking parameters i.e. Gibbs free energy, key amino acid interaction, number of clusters, and inhibition constant [20-22].

\section{Ligand-based ADMET prediction}

The computerized analysis of the pharmacokinetic properties of the ligands was obtained by using the pre-ADMET and vNN ADMET programs which were accessed online [22]. The analyzed pharmacokinetic parameters were absorption by looking at the value of Human Intestinal Absorption (HIA \%), distribution performed by the value of Plasma Protein Binding (PPB \%) and Blood-Brain Barrier (BBB), metabolism expressed by Human Liver Microsomes (HLM) and CYP inhibitors, as well as cardio and liver toxicity.

\section{RESULTS}

Table 1: Validation of molecular docking method, conducted through a re-docking process of the native ligand (BCH). It showed a good RMSD $(1.825 \AA)$ that fulfill the requirement $(<2.0 \AA)[21,22]$

\begin{tabular}{|c|c|c|c|c|c|c|}
\hline \multirow[t]{2}{*}{ Ligand } & \multirow{2}{*}{$\begin{array}{l}\text { Grid coordinate } \\
(x, y, z)\end{array}$} & \multirow{2}{*}{$\begin{array}{l}\Delta \mathrm{G} \\
(\mathrm{kcal} / \mathrm{mol})\end{array}$} & \multirow{2}{*}{$\begin{array}{l}\mathbf{K i} \\
(\mu \mathrm{M})\end{array}$} & \multirow{2}{*}{$\begin{array}{l}\text { RMSD } \\
(\AA)\end{array}$} & \multicolumn{2}{|c|}{ Interaction with LAT1 amino acid residue } \\
\hline & & & & & Hydrogen bond & Van der waals \\
\hline $\begin{array}{l}\mathrm{BCH} \\
\text { (Native Ligand) }\end{array}$ & $146.324,143.10,134.340$ & -5.25 & $\begin{array}{l}142.14 \\
\mathrm{uM}\end{array}$ & 1.825 & $\begin{array}{l}\text { Phe252, Ser66, } \\
\text { Gly67, Ile64 }\end{array}$ & $\begin{array}{l}\text { Ser338, Ala253, Ile63, Gly65, } \\
\text { Tyr289, Ile68, Tyr254 }\end{array}$ \\
\hline
\end{tabular}




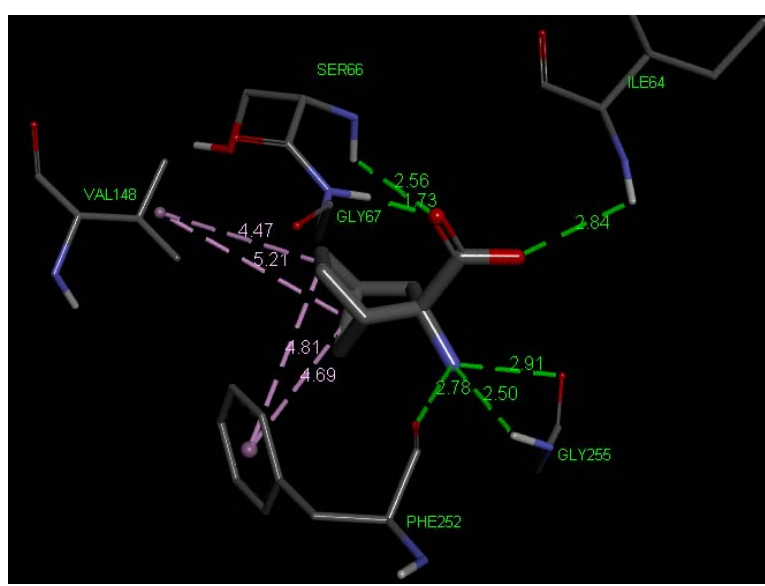

Fig. 3: The visualization of molecular interaction of BCH (native ligand) against LAT1 (PDB ID: 6IRT). BCH interacts with the key amino

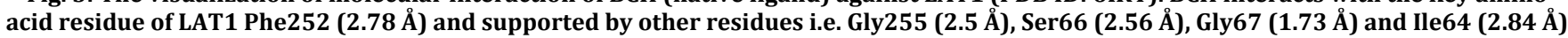
via hydrogen bonds

Table 2: Molecular docking parameters of ADFV derivatives against LAT1 (PDB ID: 6IRT). ADPB-NOTA performed as the best docked molecules with $\Delta \mathrm{G}=-5.25 \mathrm{Kcal} / \mathrm{mol}, \mathrm{Ki}=142.14 \mu \mathrm{M}$, and hydrogen bond interaction with gating residue-Phe252

\begin{tabular}{|c|c|c|c|c|}
\hline \multirow[t]{2}{*}{ Ligands } & \multirow{2}{*}{$\begin{array}{l}\Delta \mathrm{G} \\
\text { (Kcal/Mol) }\end{array}$} & \multirow{2}{*}{$\begin{array}{l}\mathbf{K i} \\
(\mu \mathrm{M})\end{array}$} & \multicolumn{2}{|l|}{ Interaction with LAT1 amino acid residue } \\
\hline & & & Hydrogen Bond & Van Der Waals \\
\hline $\mathrm{BCH}$ (Control) & $-5,25$ & 142.14 & Phe252, Gly255, Ser66, Gly67, Ile64 & Ser338, Ala253, Ile63, Gly65, Tyr289, Ile68, Tyr254 \\
\hline $\begin{array}{l}\text { ADPB } \\
\text { (Lead Compound) }\end{array}$ & -6.57 & 15.23 & Phe252, Gly255, Ser66 & $\begin{array}{l}\text { Ser144, Ser338, Gly65, Ile64, Ile68, Tyr289, Ala253, } \\
\text { Ile63, Tyr254, Gly256, Leu251, Asn404 }\end{array}$ \\
\hline ADPB-CTPA & $-1,91$ & 39,55 & $\begin{array}{l}\text { Gly255, Leu251, Lys204, Thr62, Ser338, } \\
\text { Gly341, Gly337 }\end{array}$ & $\begin{array}{l}\text { Phe252, Tyr254, Trp405, Asn404, Asn258, Phe400, } \\
\text { Gly256, Asn340, Gln197, Ser342, Gly61, Gly65, Ile63, } \\
\text { Ser144 }\end{array}$ \\
\hline ADPB-DOTA & $+2,58$ & - & $\begin{array}{l}\text { Gly61(1.97), Tyr259(2.93), Thr62(3.02), } \\
\text { Gly65(2.04), Ala253(2.44), Ser338(2.59) }\end{array}$ & $\begin{array}{l}\text { Glu136, Asn404, Leu260, Ile63, Phe400, Gln145, } \\
\text { Ser342, Ser144, Gly255, Phe252, Gly256, Ser66, ILE64, } \\
\text { Ile68, Tyr289, Gly67, Val148 }\end{array}$ \\
\hline $\begin{array}{l}\text { ADPB-H2CB- } \\
\text { DO2A }\end{array}$ & $-5,83$ & 52,03 & $\begin{array}{l}\text { Thr62, Ser338, Gly255, Phe252, Leu251, } \\
\text { Asn } 404\end{array}$ & $\begin{array}{l}\text { Gln197, Leu260, Gly61, Ile63, Gly341, Gly65, Val148, } \\
\text { Ser66, Ser342, Ser144, Gln145, Glu136, Trp405, } \\
\text { Ala253, Tyr254, Gly256 }\end{array}$ \\
\hline $\begin{array}{l}\text { ADPB-H2CB- } \\
\text { TE2A }\end{array}$ & $-5,40$ & 109,58 & $\begin{array}{l}\text { Thr62, Thr345, Gln145, Ser342, Gly341, } \\
\text { Ser338, Ser144 }\end{array}$ & $\begin{array}{l}\text { Val148, Gly255, Ile63, Gly256, Glu136, Asn404, } \\
\text { Asn258, Gly65, Ser66, Phe252 }\end{array}$ \\
\hline ADPB-NOTA & $-7,68$ & 2,36 & $\begin{array}{l}\text { Ile64(2.25), Tyr289(2.42), Gly65(1.85), } \\
\text { Ser342(3.09), Tyr259(2.56), Asn404(1.98), } \\
\text { Gly256(2.00), Asn258(2.24), Phe252(3.35) }\end{array}$ & $\begin{array}{l}\text { Gly341, Ser338, Thr62, Ala253, Tyr254, Ile63, Gly67, } \\
\text { Ser66, Gly255, Glu136, Asp116, Phe400, Ser144, } \\
\text { Gln145, Val148 }\end{array}$ \\
\hline ADPB-TETA & 7,35 & - & $\begin{array}{l}\text { Thr345, Ser342, Tyr259, Gly65, Ser338, } \\
\text { Gly61, Gly255 }\end{array}$ & $\begin{array}{l}\text { Arg141, Ser144, Gln145, Val70, Val148, Phe252, Ile147, } \\
\text { Gly67, Ser66, Lys204, Ile63, Ile64, Leu260, Gly337, } \\
\text { Gln197, Gly256, Lys132, Glu136, Asn258, Asn404 }\end{array}$ \\
\hline
\end{tabular}

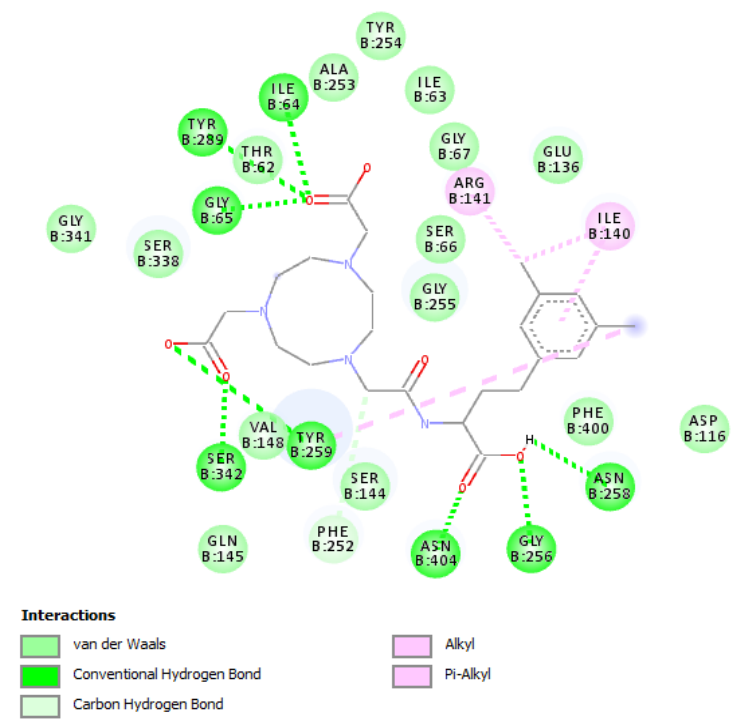

Fig. 4: The visualization of ADPB-NOTA interaction against LAT1 (PDB ID: 6IRT). The hydrogen atom at the hydroxyl group of carboxylic site acts as a hydrogen donor to the key amino acid (Asn258) 
Table 3: The ADMET parameters of ADPB derivatives, All ADPB derivatives have a good parameter of HIA, PPB, BBB, HLM, CYP inhibitor, and DILI (except ADPB-CTPA has BBB activity). Meanwhile, all ADPB derivatives have the potential to be cardiotoxic in the human body)

\begin{tabular}{|c|c|c|c|c|c|c|c|c|c|c|c|}
\hline \multirow[t]{3}{*}{ Ligands } & \multirow{3}{*}{$\begin{array}{l}\text { Absorption } \\
\text { HIA }^{\text {a }}(\%)\end{array}$} & \multicolumn{2}{|c|}{ Distribution } & \multicolumn{6}{|l|}{ Metabolism } & \multicolumn{2}{|c|}{ Toxicity } \\
\hline & & \multirow[t]{2}{*}{$\mathrm{PPB}^{\mathrm{b}}(\%)$} & \multirow[t]{2}{*}{$\mathbf{B B B}^{\mathbf{c}}$} & \multirow[t]{2}{*}{$\operatorname{HLM}^{\mathrm{d}}$ (Min) } & \multicolumn{5}{|c|}{ CYP Inhibitor } & \multirow[t]{2}{*}{ DILIe $^{e}$} & \multirow[t]{2}{*}{ Cardiotoxicity } \\
\hline & & & & & $1 \mathrm{~A} 2$ & 3A4 & 2D6 & $2 C 9$ & $2 C 19$ & & \\
\hline ADPB-CTPA & 93.45 & 41.49 & Yes & $>30$ & No & No & No & No & No & No & Yes \\
\hline ADPB-DOTA & 73.99 & 17.77 & No & $>30$ & No & No & No & No & No & No & Yes \\
\hline ADPB-H2CB-D02A & 95.93 & 24.63 & No & $>30$ & No & No & No & No & No & No & Yes \\
\hline ADPB-H3CB-TE2A & 95.90 & 16.28 & No & $>30$ & No & No & No & No & No & No & Yes \\
\hline ADPB-NOTA & 88.12 & 24.58 & No & $>30$ & No & No & No & No & No & No & Yes \\
\hline ADPB-TETA & 78.85 & 12.25 & No & $>30$ & No & No & No & No & No & No & Yes \\
\hline
\end{tabular}

Note: aHuman Intestinal Absorption (HIA): poor (0-20\%), moderate (20-70), well (70-100\%). bProtein Plasma Biding (PPB): weak (<90\%), strong (>90\%). 'Blood-Brain Barrier (BBB): enter the CNS (Yes), can not enter the CNS (No). dHuman Liposomal Metabolism (HLM): Compounds that have a half-life of $30 \mathrm{~min}$ or more expressed as $>,<30 \mathrm{~min}$. ${ }^{\mathrm{e}}$ Drug Induced Liver Injury (DILI)

\section{DISCUSSION}

In the validation process, the RMSD shows the deviation of the bond pose between the ligand that is docked with the reference bond pose (obtained from PDB). Table 1 showed that the validation process obtained 1.825 Å of RMSD that fulfilled the threshold $(<2.0 \AA ̊)[21,22]$.

In addition, $\mathrm{BCH}$ interacts with the key amino acid residue of LAT1 Phe252 (2.78 $\AA$ ) and supported by other residues i.e. Gly255 (2.5 $)$, Ser66 (2.56 ̊), Gly67 (1.73 $\AA)$, and Ile64 (2.84 $\AA$ ) via hydrogen bonds (fig. 3). In this study, BCH (as a native ligand) interacted with Ser66, Gly255, and Phe252 in the LAT-protein, the result is coherent with previous research conducted by Yan et al. (2019) [19]. This validation showed that the grid coordinates $(\mathrm{x}=146.324, \mathrm{y}=143,105$, $\mathrm{z}=134,340$ ) which are performed during the re-docking process can be used to dock the testing ligands (ADPB derivatives).

The molecular docking results showed that of the six ADPB derivatives, ADPB-NOTA performed as the best docked ligand with $(\Delta \mathrm{G}=-7.68 \mathrm{Kcal} / \mathrm{mol}, \mathrm{Ki}=2.36 \mu \mathrm{M})$ and can interact with the key amino acid residue that has a function as a gating agent of transportation functionalities of the LAT1 (table 3, fig. 4). The ability of ADPB-NOTA to interact with the key amino acid residue on the active site of the LAT1 protein (Asn25) through a strong hydrogen bond interaction $(r=2.24 \AA)$ have the potency to be a stable ligandreceptor complex in the inhibition process.

Based on molecular docking parameters (table 3), ADPB-NOTA has a better characteristic compared to $\mathrm{BCH}$ as the contrat -5.25 $\mathrm{Kcal} / \mathrm{mol}, \mathrm{Ki}=142.14 \mu \mathrm{M}$, hydrogen bond with gating residue-Phe252) as well as ADPB, which acts as the lead compound ( $\Delta \mathrm{G}=6.57 \mathrm{Kcal} / \mathrm{mol}$, $\mathrm{Ki}=15,23 \mu \mathrm{M}$, hydrogen bond with gating residue-Phe252). Meanwhile, there are two compounds that have positive $\triangle$ G (ADPB DOTA and ADPB-TETA) indicating that the ligands are unable to make a receptor-complex spontaneously (endothermic reaction) [20-22].

Prediction Absorption (HIA), distribution (PPB and BBB), metabolism (HLM and CYP Inhibitor), and toxicity (DILI and Cardiotoxicity) are important to avoid the pharmacokinetics and toxicity problem for human use. The absorption parameter was expressed as a percent of HIA which indicates drug absorption in the human intestine. This is important because it determines the amount of bioavailability and how much is absorbed in the human gut. All ADPB derivatives ranged at a well-absorbed molecule (table 3).

$\mathrm{PPB}$ and $\mathrm{BBB}$ reflect as the parameters of drug distribution. The PPB distribution profile determines the degree of drug binding to plasma proteins. Table 3 showed that the PPB value of all ADPB derivatives is less than $90 \%$ which indicates that all ADPB derivatives are weakly bound to plasma proteins so that the drug is easily partitioned in the blood to reach its target $[23,24]$. Another distribution parameter is the Blood-Brain Barrier (BBB) which shows the distribution of the drug to the CNS. Drugs intended to interact with their molecular targets in the CNS must pass through the BBB to be used as therapeutic agents. Conversely, drugs that are not intended to enter the CNS should not pass through the BBB to avoid unwanted side effects [25]. This BBB prediction can give the information of drug distribution of the CNS which ADPB-CTPA can enter the CNS and the rest are unable.
Human Liver Microsomal (HLM) and cytochrome P450 (CYP) are parameters used to predict drug metabolism profile by the liver. A drug must not be metabolized too quickly by the liver to reach an effective therapeutic concentration. HLM is a parameter to identify and eliminate compounds that are rapidly metabolized by the liver. A stable drug concentration in the human body expressed by $t_{1 / 2}$ greater than 30 min and a drug with $t_{1 / 2}$ lower than 30 needs to be excluded [26]. Based on table 3, the ADPB derivatives have good HLM parameters to be considered stable.

Besides that, CYP has an important role in metabolizing drugs. Most of drug-drug interactions (DDI) are associated with CYP inhibition. Therefore, if a drug can inhibit a certain CYP, it needs further investigation (in vitro and in vivo) to understand the possibility of drug-drug interaction with a molecule that is metabolized with a certain CYP enzyme. The five most important human CYP isoforms associated with drug metabolism are 1A2, 2C9, 2C19, 2D6, and 3A4 [27]. The CYP enzymes, particularly isoforms 1A2, 2C9, 2C19, 2D6 and $3 \mathrm{~A} 4$, are responsible for about $90 \%$ of oxidative metabolic reactions. Drugs that do not inhibit these isoforms are unlikely to be involved in DDI with many other drugs [28]. Based on table 3, ADPB derivatives are not inhibitors of CYP enzymes. Prediction of the toxicity of the test compound was carried out by looking at the parameters of DILI (Drug-Induced Liver Injury) and human Ether-àgo-go-Related Gene (hERG). DILI is an adverse reaction to a drug that occurs either as a predictable event when a person is exposed to a toxic dose of some compound or an unpredictable event with many commonly used drugs [29]. The DILI parameter represents the liver damage caused by the use of drugs. Table 3 showed that the ADPB derivatives predicted will have no DILI event in the body. Another toxicity parameter is the cardiotoxicity performed by hERG status. Drug-induced blockade of hERG function can lead to long QT syndrome, leading to arrhythmias and death [30]. Table 3 showed that the six test compounds ADPB-BFCA were predicted to be cardiotoxic. So, a further analysis (in vitro and in vivo) needs to be conducted to obtain the toxic dose of those compounds.

\section{CONCLUSION}

Based on the results, it was found that the ADPB-NOTA compound had the best interaction with LAT1 protein with a Gibbs free energy value of-7.68 kcal/mol, inhibition constant of $2.36 \mathrm{M}$, and hydrogen bonding with the key amino acid residue of LAT1 (Asn258) at the H atom of the $\mathrm{COOH}$ group. In addition, ADPB-NOTA also has a good ADME profile, but the cardiotoxicity of this molecule needs to be further analyzed to obtain data on the safety for human use.

\section{ACKNOWLEDGEMENT}

The authors are thankful to the Department of Pharmaceutical Analysis and Medicinal Chemistry, Faculty of Pharmacy, Universitas Padjadjaran.

\section{FUNDING}

This research was funded by Hibah Riset Data Pustaka dan Daring (Grants for Literature and Online Research) (No.1959/UN6.3.1/PT.00/2021) from the Directorate of Research, Community Service, Universitas Padjadjaran. 


\section{AUTHORS CONTRIBUTIONS}

All the authors contributed equally.

\section{CONFLICT OF INTERESTS}

Declared none

\section{REFERENCES}

1. WHO [internet]. Available from: https://gco/today/data/factsheets/cancers/39-All-cancersfact-sheet.pdf. [Last accessed on 10 Jan 2021]

2. Wong $\mathrm{CH}$, Siah KW, Lo AW. Estimation of clinical trial success rates and related parameters. Biostatistics. 2019 Apr 1;20(2):273-86.

3. Lin A, Giuliano CJ, Palladino A, John KM, Abramowicz C, Yuan ML, Sausville EL, Lukow DA, Liu L, Chait AR, Galluzzo ZC, Tucker C, Sheltzer JM. Off-target toxicity is a common mechanism of action of cancer drugs undergoing clinical trials. Sci Transl Med. 2019;11(509):eaaw8412. doi: 10.1126/scitranslmed.aaw8412, PMID 31511426.

4. Sgouros G, Bodei L, McDevitt MR, Nedrow JR. Radiopharmaceutical therapy in cancer: clinical advances and challenges. doi: 10.1038/s41573-020-0073-9 [published correction appears in Nat Rev Drug Discov. 2020 Sep 7;19(9):589-608. doi: 10.1038/s41573-020-0073-9.

5. Herrmann K, Schwaiger M, Lewis JS, Solomon SB, McNeil BJ, Baumann M, Gambhir SS, Hricak H, Weissleder R. Radiotheranostics: a roadmap for future development. Lancet Oncol. 2020;21(3):e146-56. doi: 10.1016/S14702045(19)30821-6, PMID 32135118.

6. Achmad A, Lestari S, Holik HA, Rahayu D, Bashari MH, Faried A Kartamihardja AHS. Highly Specific L-Type Amino Acid Transporter 1 Inhibition by JPH203 as a Potential Pan-Cancer Treatment. Processes. 2021;9(7):1170. doi: 10.3390/pr9071170.

7. Kanai Y, Segawa H, Miyamoto Ki, Uchino H, Takeda E, Endou H. Expression cloning and characterization of a transporter for large neutral amino acids activated by the heavy chain of $4 \mathrm{~F} 2$ antigen (CD98). J Biol Chem. 1998;273(37):23629-32. doi: 10.1074/jbc.273.37.23629, PMID 9726963.

8. Yanagida O, Kanai Y, Chairoungdua A, Kim DK, Segawa H, Nii T, Cha SH, Matsuo H, Fukushima J, Fukasawa Y, Tani Y, Taketani Y, Uchino H, Kim JY, Inatomi J, Okayasu I, Miyamoto K, Takeda E, Goya T, Endou H. Human L-type amino acid transporter 1 (LAT1): characterization of function and expression in tumor cell lines. Biochim Biophys Acta. 2001;1514(2):291-302. doi: 10.1016/s0005-2736(01)00384-4, PMID 11557028.

9. Kim DK, Ahn SG, Park JC, Kanai Y, Endou H, Yoon JH. Expression of L-type amino acid transporter 1 (LAT1) and 4F2 heavy chain (4F2hc) in oral squamous cell carcinoma and its precursor lesions. Anticancer Res. 2004;24(3a):1671-5.

10. Honjo H, Kaira K, Miyazaki T, Yokobori T, Kanai Y, Nagamori S, Oyama T, Asao T, Kuwano H. Clinicopathological significance of LAT1 and ASCT2 in patients with surgically resected esophageal squamous cell carcinoma. J Surg Oncol. 2016;113(4):381-9. doi: 10.1002/jso.24160, PMID 26936531.

11. Ichinoe M, Mikami T, Yoshida T, Igawa I, Tsuruta T, Nakada N, Anzai N, Suzuki Y, Endou H, Okayasu I. High expression of L-type amino-acid transporter 1 (LAT1) in gastric carcinomas: comparison with non-cancerous lesions. Pathol Int. 2011;61(5):281-9. doi: 10.1111/j.1440-1827.2011.02650.x, PMID 21501294.

12. Segawa A, Nagamori S, Kanai Y, Masawa N, Oyama T. L-type amino acid transporter 1 expression is highly correlated with Gleason score in prostate cancer. Mol Clin Oncol. 2013;1(2):274-80. doi: 10.3892/mco.2012.54, PMID 24649160.

13. Kaira K, Oriuchi N, Imai H, Shimizu K, Yanagitani N, Sunaga N, Hisada T, Tanaka S, Ishizuka T, Kanai Y, Endou H, Nakajima T, Mori M. Prognostic significance of L-type amino acid transporter 1 expression in resectable stage I-III nonsmall cell lung cancer. Br J Cancer. 2008;98(4):742-8. doi: 10.1038/sj.bjc.6604235, PMID 18253116.

14. Kaira K, Sunose Y, Ohshima Y, Ishioka NS, Arakawa K, Ogawa T, Sunaga N, Shimizu K, Tominaga H, Oriuchi N, Itoh H, Nagamori S, Kanai Y, Yamaguchi A, Segawa A, Ide M, Mori M, Oyama T,
Takeyoshi I. Clinical significance of L-type amino acid transporter 1 expression as a prognostic marker and potential of new targeting therapy in biliary tract cancer. BMC Cancer. 2013;13:482. doi: 10.1186/1471-2407-13-482, PMID 24131658.

15. Kaira K, Sunose Y, Arakawa K, Ogawa T, Sunaga N, Shimizu K, Tominaga H, Oriuchi N, Itoh H, Nagamori S, Kanai Y, Segawa A, Furuya M, Mori M, Oyama T, Takeyoshi I. Prognostic significance of L-type amino-acid transporter 1 expression in surgically resected pancreatic cancer. Br J Cancer. 2012;107(4):632-8. doi: 10.1038/bjc.2012.310, PMID 22805328.

16. Furuya M, Horiguchi J, Nakajima H, Kanai Y, Oyama T. Correlation of L-type amino acid transporter 1 and CD98 expression with triple negative breast cancer prognosis. Cancer Sci. 2012;103(2):382-9. doi: 10.1111/j.13497006.2011.02151.x, PMID 22077314.

17. Hayase S, Kumamoto K, Saito K, Kofunato Y, Sato Y, Okayama H, Miyamoto K, Ohki S, Takenoshita S. L-type amino acid transporter 1 expression is upregulated and associated with cellular proliferation in colorectal cancer. Oncol Lett. 2017;14(6):7410-6. doi: 10.3892/ol.2017.7148, PMID 29344181 .

18. Singh N, Scalise M, Galluccio M, Wieder M, Seidel T, Langer T, Indiveri C, Ecker GF. Discovery of potent inhibitors for the large neutral amino acid Transporter 1 (LAT1) by structure-based methods. Int J Mol Sci. 2018;20(1):27. doi: 10.3390/ijms20010027, PMID 30577601.

19. Yan R, Zhao X, Lei J, Zhou Q. Structure of the human LAT14F2hc heteromeric amino acid transporter complex. Nature. 2019;568(7750):127-30. doi: 10.1038/s41586-019-1011-z, PMID 30867591.

20. Sherman W, Beard HS, Farid R. Use of an induced fit receptor structure in virtual screening. Chem Biol Drug Des. 2006;67(1):83-4. doi: 10.1111/j.1747-0285.2005.00327.x, PMID 16492153

21. Ibrahim FM, Holik HA, Achmad A. In-silico studies of amentoflavone and its derivatives against sars-cov-2. Rasayan J Chem. 2021;14(3). doi: 10.31788/RJC.2021.1436172.

22. Hidayat S, Ibrahim FM, Pratama KF, Muchtaridi M. The interaction of alpha-mangostin and its derivatives against main protease enzyme in covid-19 using in silico methods. J Adv Pharm Technol Res. 2021;12(3):285-90. doi: 10.4103/japtr.JAPTR_299_20, PMID 34345609.

23. Yonsei engineering research complex. Descript Pre-ADMET. 2017.

24. Du X, Li Y, Xia YL, Ai SM, Liang J, Sang P, Ji XL, Liu SQ. Insights into protein-ligand interactions: mechanisms, models, and methods. Int J Mol Sci. 2016;17(2):144. doi: 10.3390/ijms17020144, PMID 26821017.

25. Garg P, Verma J. In silico prediction of blood brain barrier permeability: an Artificial Neural Network model. J Chem Inf Model. 2006;46(1):289-97. doi: 10.1021/ci050303i, PMID 16426064.

26. Liu R, Schyman P, Wallqvist A. Critically assessing the predictive power of QSAR models for human liver microsomal stability. J Chem Inf Model. 2015;55(8):1566-75. doi: 10.1021/acs.jcim.5b00255, PMID 26170251

27. Guengerich FP. Cytochrome P450s and other enzymes in drug metabolism and toxicity. AAPS J. 2006;8(1):E101-11. doi: 10.1208/aapsj080112, PMID 16584116.

28. Williams JA, Hyland R, Jones BC, Smith DA, Hurst S, Goosen TC, Peterkin V, Koup JR, Ball SE. Drug-drug interactions for UDPglucuronosyltransferase substrates: a pharmacokinetic explanation for typically observed low exposure (AUCi/AUC) ratios. Drug Metab Dispos. 2004;32(11):1201-8. doi: 10.1124/dmd.104.000794, PMID 15304429.

29. Andrade RJ, Chalasani N, Bjornsson ES, Suzuki A, Kullak-Ublick GA, Watkins PB, Devarbhavi H, Merz M, Lucena MI, Kaplowitz N, Aithal GP. Drug-induced liver injury. Nat Rev Dis Primers. 2019;5(1):58. doi: 10.1038/s41572-019-0105-0, PMID 31439850.

30. Schyman P, Liu R, Wallqvist A. General purpose 2D and 3-D similarity approach to identify hERG blockers. J Chem Inf Model. 2016;56(1):213-22. doi: 10.1021/acs.jcim.5b00616, PMID 26718126. 